\title{
El itinerario fotoperiodístico de Agustín Victor Casasola, 1901-1910
}

\author{
Daniel Escorza Rodríguez*
}

\begin{abstract}
Resumen:
Mi propósito en este artículo es revisar, a través de un caso monográfico, la aseveración de que con el movimiento revolucionario iniciado en 1910 se registraron nuevos hechos y nuevas formas de fotografías. A través de un trabajo como el de Casasola que recorreremos en poco más de 10 años, de 1901 a 1913, revisaremos los principales cambios, las continuidades y la visualidad que se fue gestando en estos años decisivos para la historia de la fotografía en México.
\end{abstract}

\section{Palavras-chaves: Fotografia, Fotógrafo, Revolución Mexicana, Agustin V. Casasola}

Hacia finales del siglo XIX y principios del siglo XX, la sociedad mexicana en general acusaba una mutación en el modo de aprehender la realidad, cuyo eje fundamental fue la reproducción masiva de la imagen analógica. En este entrecruzamiento de imágenes aparecieron diversos artefactos que produjeron una nueva visualidad alejada de la pintura, el grabado o la litografía, todavía imperantes hasta finales del siglo XIX.

De estos artilugios, por lo menos en la ciudad de México, podemos destacar las vistas estereoscópicas, las tarjetas postales, cuya venta masiva comenzó en la década de los ochenta del siglo XIX, el cinematógrafo, y desde luego, la reproducción fotográfica de medio tono en diarios y magazines ilustrados ${ }^{1}$.

La conjunción de imágenes tomadas de lo que pretendía ser "la realidad" sorprendieron a los habitantes de las principales ciudades del país y provocó la visualización masiva de nuevos formatos, tanto en fotos fijas como en movimiento, en el caso del cine. En esta vorágine de visualidad, como señala Alberto del Castillo, "el cambio más importante en los usos y la recepción de las imágenes se produjo con la incorporación de la fotografía a los magazines ilustrados y posteriormente a la prensa periódica debido al empleo de las placas de fotograbado y a los procesos de medio tono..."2. Pero, ¿en qué consistió ese cambio?, o ¿de qué manera se manifestó en el imaginario de entonces?

Todos estos nuevos espacios de divugación - por llamarlos de alguna manera comenzaron a otorgarle otro sentido a las fotografías, y por lo tanto a sus posibles 
lecturas, que atravesaron el tamiz de la visualidad masiva, y por primera vez se acercaron a borrar la delgada línea entre lo público y lo privado. De esta manera, el álbum de familia dejó de ser el objeto fotográfico por antonomasia, y ahora surgía el magazine, la revista ilustrada, los periódicos, y en general las publicaciones que contenían las fotografías del momento.

En el presente artículo intento diseccionar el trabajo de un foto-reportero, cuya labor correspondía a una nueva dinámica del quehacer periodístico. En este sentido, revisaremos la idea subyacente en una gran parte de trabajos sobre la historia de la fotografía, de que la revolución mexicana cambió las formas, las ideas, los escenarios y hasta los fotógrafos en la manera de retratar. ${ }^{3}$ A través de un trabajo como el de Casasola que recorreremos en poco más de 10 años, de 1901 a 1913, revisaremos los principales cambios, las continuidades y la visualidad que se fue gestando en estos años decisivos para la historia de la fotografía en México.

Mi propósito en este artículo es revisar, a través de un caso monográfico, la aseveración de que con el movimiento revolucionario iniciado en 1910 se registraron nuevos hechos y nuevas formas de fotografías. Al respecto, cabe preguntarse ¿la Revolución cambió el ideal de estas fotografías, con encuadres arriesgados, dejando atrás el pictorialismo, por ejemplo? ¿No se tratará más bien de un ejercicio fotoperiodístico que fue evolucionando y cuyo hilo conductor fue la técnica o la tecnología fotográfica?

Hasta antes del inicio de la Revolución mexicana en 1910, Agustín Víctor Casasola había incursionado en el fotoperiodismo, lo cual le llevó a trabajar en más de seis periódicos de la capital de la república. Sabemos que desde 1894 ingresó como reporter al periódico El Liberal. ${ }^{4}$ Posteriormente estuvo laborando en El Correo Español, El Popular, El Universal y El Globo; pero fue en el año de 1901, cuando comenzó a tomar fotografías para ilustrar sus artículos.

En mayo de ese año, el periódico El Tiempo, de Victoriano Agüeros, comenzó a publicar las primeras fotografías de Casasola, que versaban sobre algunos eventos sociales de la ciudad de México. En estos años de 1901 a 1905, aproximadamente, nuestro fotógrafo registró los eventos cívico-sociales y a publicar sus fotografías en el Semanario Literario Ilustrado del mismo periódico.

Posteriormente, en 1905, ingresó al equipo del periódico El Imparcial, recomendado por Victoriano Agüeros a Rafael Reyes Spíndola. En este diario, Agustín continuó en su labor fotoperiodística, de tal suerte que para 1910 ya contaba con una práctica muy importante en el nuevo oficio. En este último año, el programa 
conmemorativo de las Fiestas del Centenario de la Independencia de México convocó a numerosos fotógrafos de los distintos periódicos y revistas que circulaban en la época, con el propósito de registrar tales acontecimientos. ${ }^{5}$ Para entonces, Casasola ya gozaba de un cierto prestigio labrado a lo largo de 10 años de labor ininterrumpida.

\section{Agustín V. Casasola en El Semanario Literario Ilustrado, de El Tiempo}

El $1^{\circ}$ de enero de 1901, apareció el número inicial del semanario ilustrado del diario El Tiempo, señero periódico fundado y dirigido por don Victoriano Agüeros. El propósito de esta publicación, denominada inicialmente El Tiempo Literario Ilustrado, era ofrecer al lector notas de literatura, historia, bellas artes, variedades, y otros temas, con la particularidad de que incluía en sus páginas varias fotografías. ${ }^{6} \mathrm{Si}$ bien, en sus primeros meses de existencia, la mayor parte de las fotografías publicadas no acreditaban el nombre de su autor, como era la costumbre, muy pronto se fueron incorporando los créditos, tanto de quien hacía el fotograbado como del fotógrafo. ${ }^{7}$

A partir de la edición del 13 de mayo de 1901, el Semanario Ilustrado comenzó a incluir con mayor frecuencia el crédito de las fotos, adjudicándoselas al reportero Agustín Víctor Casasola. En ese entonces, el joven reportero comenzó a realizar imágenes destinadas a complementar sus propias notas en la publicación semanaria. Es posible que la intención original de los redactores de El Tiempo Ilustrado haya sido la inclusión de la fotografía como complemento de la nota escrita. Al respecto es sugerente el texto editorial de la publicación en esta primera serie de fotografías tomadas por Casasola, referente a las maniobras militares en el campo de "La Vaquita", en donde se señala:

Con el fin de dar a conocer a nuestros lectores una idea de lo que fueron las fiestas militares organizadas por la Secretaría de Guerra para celebrar el XXXIX aniversario de la Batalla del 5 de mayo de 1862 en Puebla, nuestro reporter, el Sr. Casasola tomó varias fotografías en el campo de la Vaquita, las cuales publicamos en el presente número. ...

En efecto, se trata de otorgar a la imagen la calidad de complemento de la noticia, al recalcar que se quiere dar a conocer una "idea" de estas fiestas.

La fotografía en cuestión aborda diversos aspectos de las fiestas del 5 de mayo, supervisadas invariablemente por el presidente de la República. Algunas de ellas están editadas en la publicación en una especie de formato panorámico, y en general todas 
acusan una distancia considerable del objetivo, es decir, el fotógrafo permanecía muy alejado de las personas o actos a retratar. Hasta donde se sabe, estas son las primeras fotografías de Casasola en donde se le reconoce expresamente su autoría.

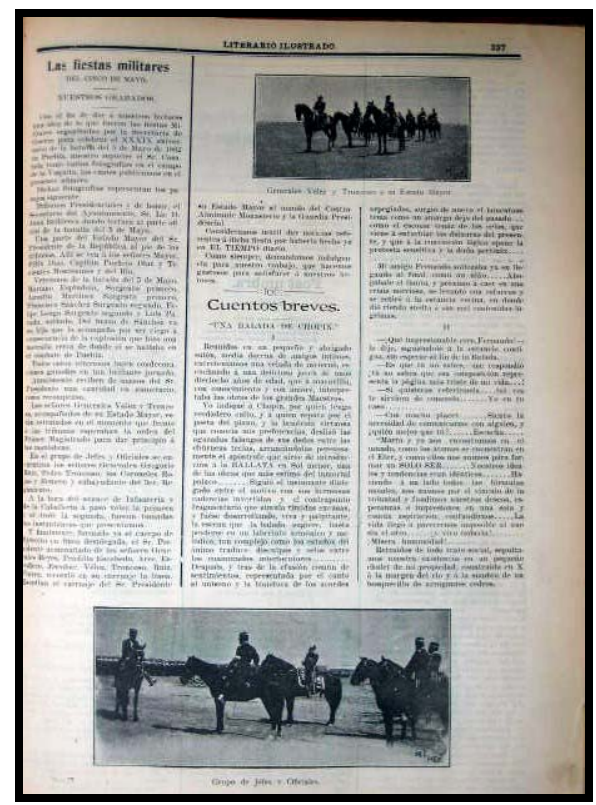

Imagen 1 - Semanario Literario Ilustrado, México D.F., 13 de mayo, 1901.

Los primeros ejercicios fotográficos del reporter Agustín V. Casasola oscilaron entre el complemento gráfico del texto noticioso y una especie de dispositivo nostálgico de la realidad. En un artículo que escribió, relativo a la demolición de una casa de "Puentecitos", en el centro de la ciudad de México, Casasola se refiere a sus propias fotografías con cierto sentido de la memoria social cuando señala que:

Es muy curiosa la casa como antigüedad, y como muy pronto será demolida, hemos tomado las fotografías que acompañamos para conservar el recuerdo de una de tantas casas del México viejo, que diariamente van desapareciendo. ${ }^{9}$

De esta manera vemos cómo Agustín comenzó a observar su realidad en su calidad simultánea de reporter y de fotógrafo. ${ }^{10}$ El sentido utilitario de la fotografía para él era "conservar el recuerdo", es decir, hay una intención de tomar las fotos, como parte de un realidad que se fijaba, o se congelaba en una imagen. En sus actividades cotidianas a partir de 1901, lo mismo acudía con su cámara a la recepción de ministros o diplomáticos, que a bautizos o matrimonios de familias acomodadas de la capital de la República. La mayoría de sus fotografías publicadas en estos primeros años del siglo XX acompañan las crónicas y noticias sobre novilladas y corridas de toros; kermeses en los alrededores de la ciudad como: en Mixcoac, en Tacubaya, o en Coyoacán; notas 
referentes a los ferrocarriles eléctricos, a instituciones como el Hospital General, al Panteón, o a la colocación de las primeras piedras ya sea del nuevo edificio del Correo, o de la columna conmemorativa de la Independencia; las fiestas del Club Hípico Alemán, de la Junta Española de Covadonga en el Tívoli del Eliseo, o de las Flores en el centro de la ciudad; narraciones de los ejercicios militares en el campo de La Vaquita, o de ceremonias cívicas en las que participaba el presidente de la República.

Pero no sólo Casasola cubría los acontecimientos de la ciudad de México. Las exigencias del semanario lo enviaron a visitar algunos estados del centro de la República, como Morelos, Querétaro, Guanajuato, Veracruz y Guerrero, entre otros. En este último estado realizó una visita a las grutas de Cacahuamilpa, en donde tomó fotografías del interior de este monumento natural. Asimismo, para marzo de 1902, Agustín Víctor Casasola fue enviado a Veracruz a cubrir el evento de la inauguración de los trabajos del puerto. En esta ocasión, el reporter-fotógrafo tomó una serie de fotografías del presidente Díaz, que combinaba todavía un tanto la preceptiva del estudio fotográfico con los nuevos códigos de la instantánea.

A ese respecto, en una de ellas el presidente y su comitiva posan de manera muy formal, sobre el muelle. La vista de los retratados se dirige hacia la lente de Casasola, expectantes ante la acción del obturador. Algunos instantes después, el presidente se alista para abordar uno de los buques, y en ese preciso momento Casasola capta otra imagen, justo cuando nadie es consciente del obturador, sólo el que toma la foto. Las imágenes publicadas en el semanario, de acuerdo al fotógrafo, nos dan una "idea" del evento; es decir, complementan la información textual. ${ }^{11}$ Nos encontramos entonces ante la protohistoria de la fotografía periodística cuya función primaria es ser un intérprete de la realidad.

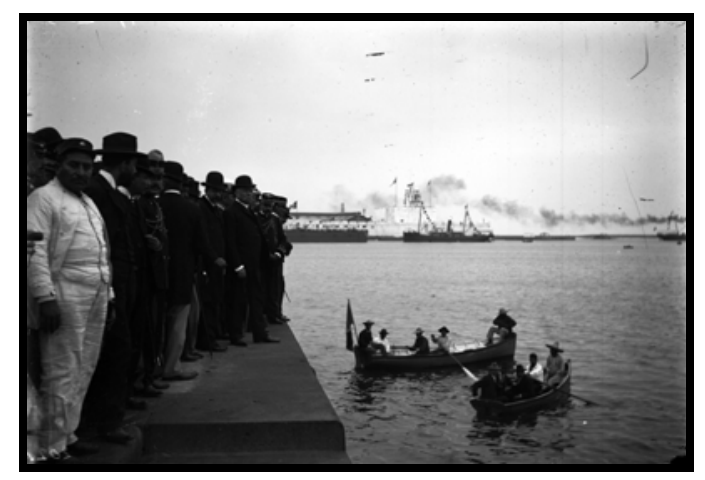

Imagen 2 -No. Inventario 34478, Negativo gelatina sobre vidrio

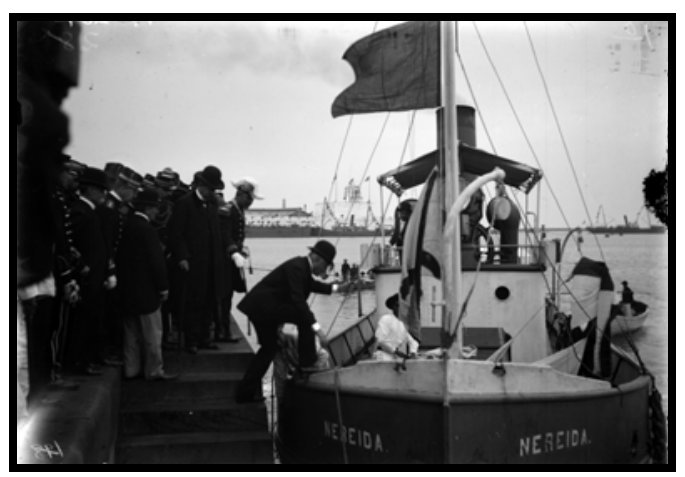

Imagen 3 - No. Inventario 34484, negativo gelatina sobre vidrio

Quizá lo más vistoso de esta etapa de nuestro fotógrafo sea el hecho de que 
aunque en sus trabajos periodísticos se le otorgaba el crédito de sus fotos, su tarea fundamental seguía siendo la de "reportear", o escribir el texto de la noticia. Esto explica que en 1903 haya formado parte del grupo fundador de la Asociación Mexicana de Periodistas, junto con otros redactores de entonces, como Fortunato Herrerías, Carlos del Valle Gargen, Pedro Hagelstein, Miguel Necochea, Antonio Rivera de la Torre, Federico García y Alva, entre otros. Cabe señalar que todos ellos son reporters, y ninguno era fotógrafo, salvo el propio Casasola. ${ }^{12}$ El antecedente de esta organización fue la "Junta de Reporters de la Ciudad de México", formada en febrero de ese mismo año. ${ }^{13}$

En estos primeros años Casasola concibe a la fotografía como un certificado de veracidad que refuerza al texto del periódico. Su intención primaria al tomar las fotos era "ilustrar" lo que escribía para el periódico, o para el semanario ilustrado, de tal forma que la fotografía para él comenzó a ser un complemento al modo de informar, por ejemplo en la cuestión de cómo se producía la tracción eléctrica de los nuevos vehículos usados en el Distrito Federal, hacia 1901, señalaba:

Tal consideración - escribió Casasola -, nos hizo solicitar del caballeroso Sr. D. Carlos Creeg, Gerente General de la Compañía, el permiso correspondiente a fin de visitar la planta eléctrica de la Indianilla para tomar fotografías y obtener datos y así poder dar una información gráfica de lo relativo a la tracción eléctrica. ... Las fotografías que acompañamos a esta información darán una ligera idea de la magnitud de la instalación. ... ${ }^{14}$

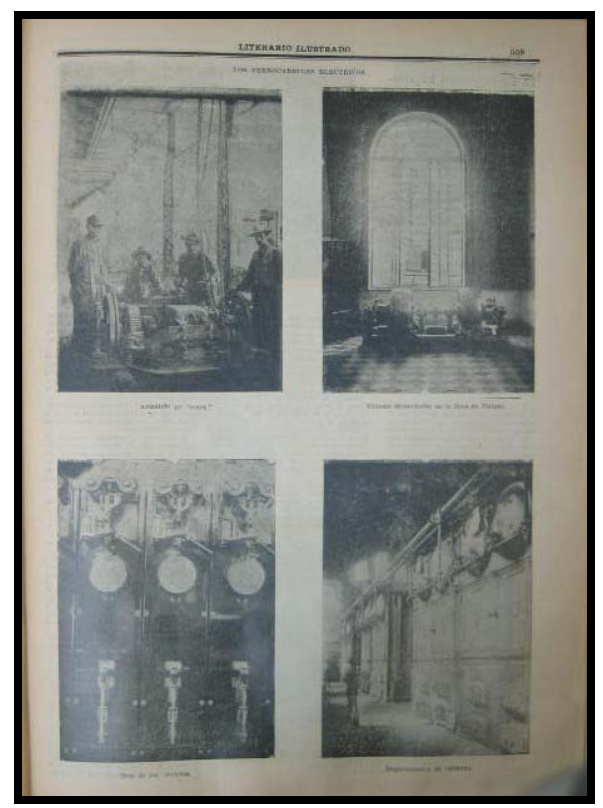

Imagen 4 - Semanario Literario Ilustrado, 21 de octubre de 1901. 
Para contextualizar las imágenes publicadas entre 1901 y 1905, es preciso no perder de vista la relación indisoluble entre el texto y la imagen, en donde el primero es el elemento esencial de la publicación, ya que la fotografía se concibe como el "reforzamiento de una idea, o la constatación de lo que señala el texto. En este sentido, y siguiendo a Ariel Arnal,

la fotografía ... "acompaña" al texto (ya sea nota periodística o pie de foto) ... y es el conjunto del mensaje el que otorga veracidad a ambos, es decir; la fotografía otorga certificado de veracidad en la medida en que la recreación del texto resulta verosímil, pero a la vez, el texto escrito es reforzado por la imagen gráfica. ${ }^{15}$

\section{Una nueva visualidad}

Después de sus primeras fotos emplazadas en las páginas interiores del magazine ilustrado, Agustín Víctor Casasola tuvo acceso muy pronto a las portadas, que en muchas publicaciones ilustradas de ese entonces estaban reservadas a los fotógrafos de estudio, como los afamados hermanos Valleto, Emilio Lange, Octaviano de la Mora, o a trabajos de corte un tanto pictorialista.

Una de las primeras portadas de Casasola es la fotografía del Arzobispo de Guadalajara, con motivo de la peregrinación que hizo un grupo de fieles jaliscienses a la Basílica de Guadalupe, en la ciudad de México, en abril de 1903. ${ }^{16}$ Sin embargo, esta fotografía no muestra el retrato del jerarca, sino hace una vista del interior de la iglesia, y al fondo el prelado católico, con su séquito eclesiástico, en una composición tradicional que no implica movimiento alguno.

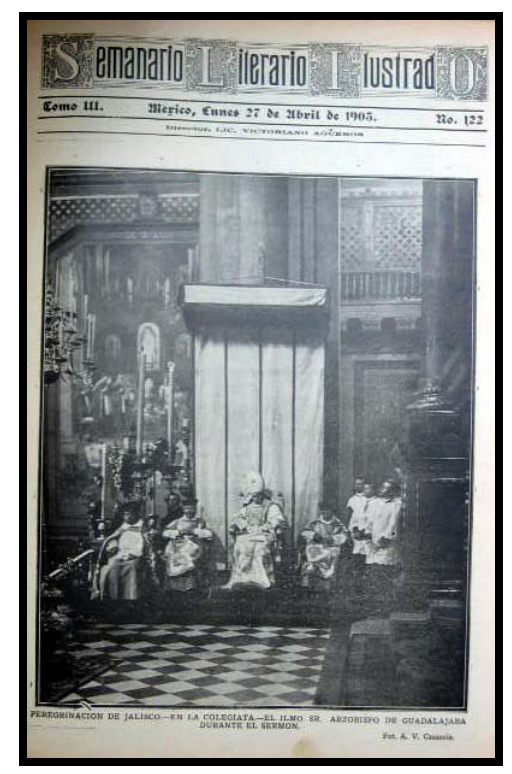

Imagen 5 - Semanario Literario Ilustrado, 27 de abril de 1903. 
En noviembre de ese mismo año, aparece otra portada de Casasola que remite a la noción de la instantaneidad. ${ }^{17}$ En ella se observa al presidente Porfirio Díaz, en su visita a la ciudad de Guanajuato, acompañado de su comitiva que desciende de una escalinata, en el momento en que saluda de mano a una persona, y es captado por la cámara. El pie de foto funciona como un texto que ancla y orienta la mirada del lector sobre la imagen de un presidente de la República que tiene la deferencia de saludar a un personaje anónimo, y que reza: "El General Díaz da la mano a un barretero al salir de la iglesia 'La Valenciana' en Guanajuato (Fotografía tomada por nuestro reporterfotógrafo Sr. A.V. Casasola)".

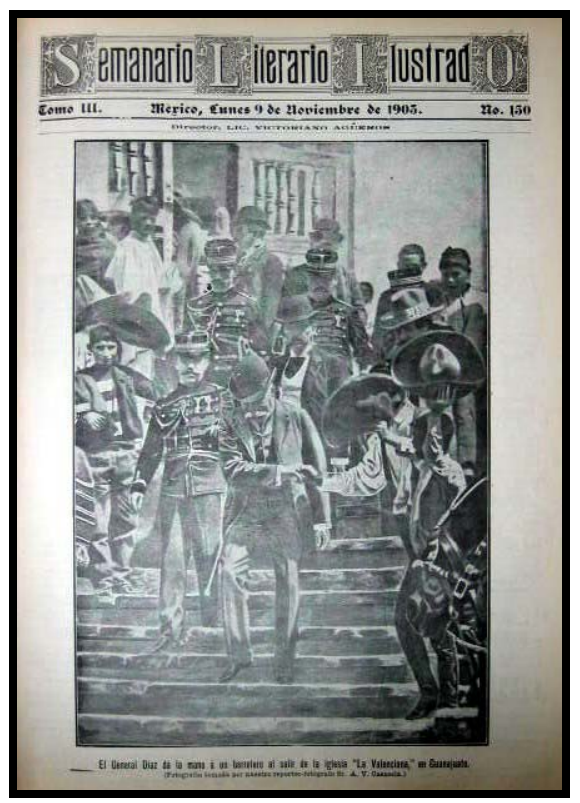

Imagen 6 - Semanario Literario Ilustrado, 9 de noviembre de 1903.

Esta singular portada es uno de los primeros casos de trastocamiento consciente de la imagen en el fotoperiodismo mexicano, ya que un acercamiento a la placa original nos permite observar una mayor información visual. ${ }^{18}$ En el negativo original, Casasola realiza una imagen que podríamos llamar como la "captura del momento", es decir, la imagen que el fotógrafo encuadró y registró en su cámara, así haya sido una puesta en escena, una puesta en imagen, o una ficción. El hecho es que, en ese preciso instante, el fotógrafo captó la escena de todo el contexto en que se mueve Díaz y su comitiva, y eso fue lo que se plasmó en el negativo de cristal. A los lados vemos habitantes de la ciudad de Guanajuato, y al centro un militar que obstruye la vista del saludo presidencial al minero. 


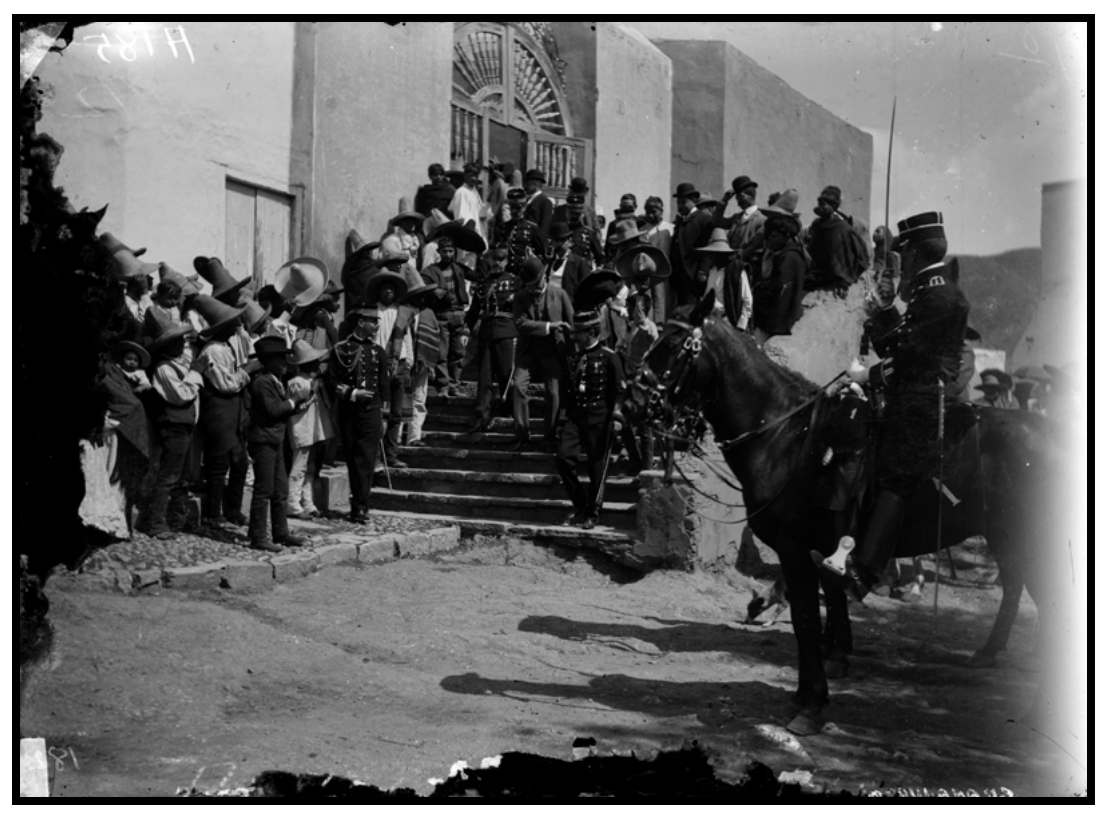

Imagen 7 - Fondo Casasola, INAH, No. inventario 5305. Negativo gelatina sobre vidrio.

Esta "captura del momento" fue modificada conscientemente por el fotograbador, tal y como podemos observar en la edición de la revista, en donde no sólo enfoca la visualidad hacia el presidente, sino que elimina al militar que va adelante, con el propósito de que se vea con mayor claridad el momento en que estrecha la mano del minero anónimo. Por lo tanto, la portada del 9 de noviembre de 1903 introduce la noción de lo que llamaremos la "invención postemporal de la imagen", es decir, la modificación que se hace a una imagen, ya sea por su recorte, modificación, o inclusive el cambio del sentido del texto que la acompaña respecto de lo que se halla en el momento de la captura. Estas dos categorías de análisis pueden servirnos para posteriores aproximaciones a las formas en las que han circulado las fotos en los medios impresos.

Con este iconotexto como portada, la figura de Díaz abandona la imagen hierática multirreproducida en diarios y semanarios, y se convierte en un presidente que es captado en una "instantánea", cuya imagen de autoridad es reforzada con la composición en contrapicada. No obstante, el hecho de que el presidente salude a un barretero introduce un tono popular en la imagen, todo ello en el marco de un acto cotidiano de su visita a la mina de la Valenciana, en la ciudad de Guanajuato.

Esta fotografía es sólo un ejemplo de la función social que empezó a adquirir la edición de la imagen en la construcción del imaginario del poder no sólo en los diarios y revistas ilustradas, sino en todos los artefactos visuales que iban desde las tarjetas postales hasta el cine. Recordemos que es precisamente en estos primeros años del siglo 
cuando el cinematógrafo se convierte en un vehículo importante de transmisión de la realidad, cuyo personaje principal era el propio presidente Porfirio Díaz, tal y como lo señala Aurelio de los Reyes:

La prensa cubría su figura [la de Díaz] con una aureola de majestad y grandeza; la rodeaba de leyenda, la mitificaba. Se le presentaba magnánimo, abnegado, responsable, superdotado, como el "hombre necesario para México". ... y aunque los analfabetas eran muchos y desconocían lo escrito sobre Díaz, la comunicación oral transmitía su leyenda y el cinematógrafo difundía su figura ... Es evidente que el éxito de la figura de Díaz radicaba en su popularidad, pero también en cierta medida a que un gran número de espectadores veía por primera vez su retrato. ${ }^{19}$

En otros casos, el Semanario otorga la preeminencia visual a Díaz, en imágenes que originalmente empequeñecían la figura del presidente, tal y como se puede observar en la fotografía relativa a la visita de Díaz a las nuevas instalaciones del Hospicio de la ciudad de México. En este caso, el Semanario hizo la edición de la foto, con un acercamiento a Díaz, ya que el negativo original muestra en primer plano, a la izquierda, algunos personajes no identificados y que visualmente son los más importantes en la imagen. Aqui nos encontramos de nueva cuenta con la noción de la "invención postemporal" de la realidad, ya que el editor, o fotograbador del periódico encierra en un círculo la figura de Díaz, lo cual modifica sustancialmente la escena original de la "captura del momento".

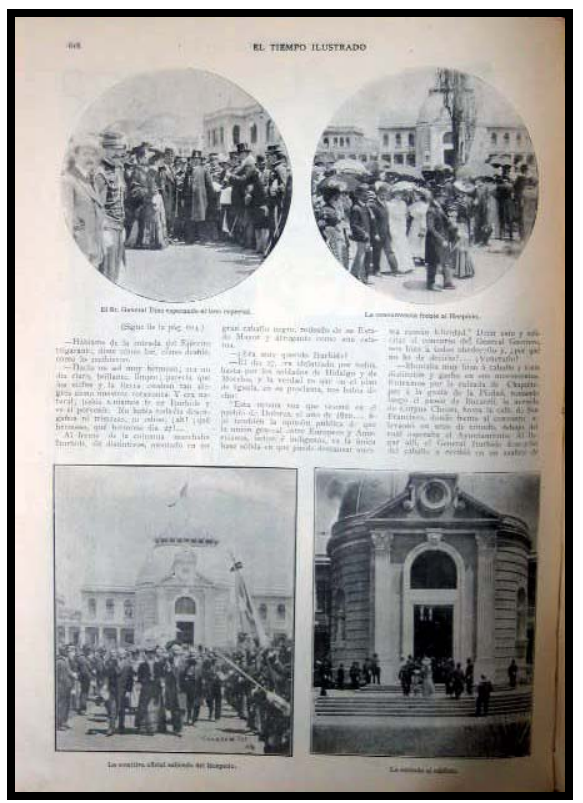

Imagen 8 - Semanario Literario Ilustrado, 24 de septiembre de 1905

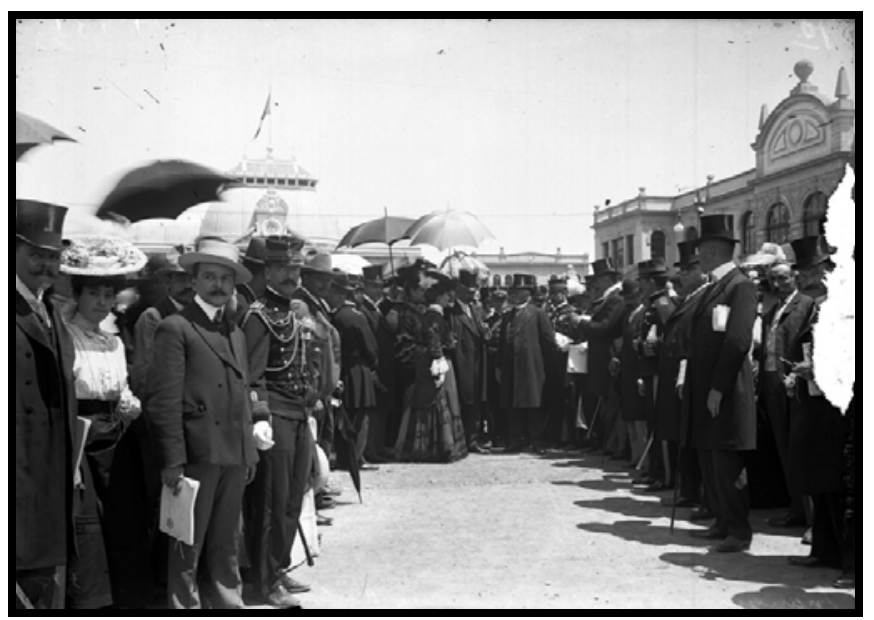

Imagen 9 - No. inventario 5749. Negativo gelatina sobre vidrio. 
A pesar de la aparición de fotografías en las portadas de las revistas y de la práctica fotográfica que iba adquiriendo en estos años, tanto Casasola como los demás fotógrafos de la prensa nunca fueron considerados como los grandes artistas de la lente, en constraste con los fotógrafos de estudio. En las propias páginas del Semanario, hacia 1906 se mencionaban a quienes se consideraba los fotógrafos mexicanos más influyentes de esos años, todos ellos con experiencia en fotografía de gabinete, y quienes - según los editores - habían "conseguido elevar a verdadero arte lo que anteriormente era una mera afición o un "modus vivendi". ${ }^{20}$ Entre ellos se mencionaban a: Manuel Torres, Antíoco Cruces, los hermanos Valleto, Octaviano de la Mora, Ramón Peón del Valle, Frank L. Clarke, Emilio Lange y Emilio Rivoire. Desde luego, Casasola no estaba considerado entre las "celebridades y artistas" de la fotografía en México. Tampoco los otros fotorreporteros contemporáneos y además en activo, como Antonio Garduño, Jerónimo Hernández, Manuel Ramos, Abraham Lupercio, Víctor León, Luis Santamaría y Adrián Hernández, entre otros.

En estos primeros años del siglo XX, Agustin V. Casasola experimentó con las distintas formas de hacer fotografía, desde los retratos, hasta la tentación "artística" o pictorialista, tan en boga durante ese lapso. Pero, además, ejercía una especie de iniciativa propia para elegir sus imágenes. De hecho, da la impresión de que, como fotógrafo, no se limitaba a recibir órdenes de los redactores, sino que aprovechaba alguna circunstancia para tomar otra fotografía.

Tal fue el caso de un encargo que le asignaron para "ilustrar" una biografía de Pelegrín Clavé que escribía Manuel Revilla para el semanario de El Tiempo. En esa ocasión, acudió a registrar fotográficamente algunos óleos en la Academia de San Carlos, y aprovechó el momento para hacer un retrato de la señorita Lucía Merkens. ${ }^{21}$ En este retrato se observa a la joven estudiante, vestida de negro, sentada en una especie de escalera, frente a un caballete. La composición de la imagen corresponde al retrato tradicional en el que se observa una estética propia de los retratos decimonónicos. 


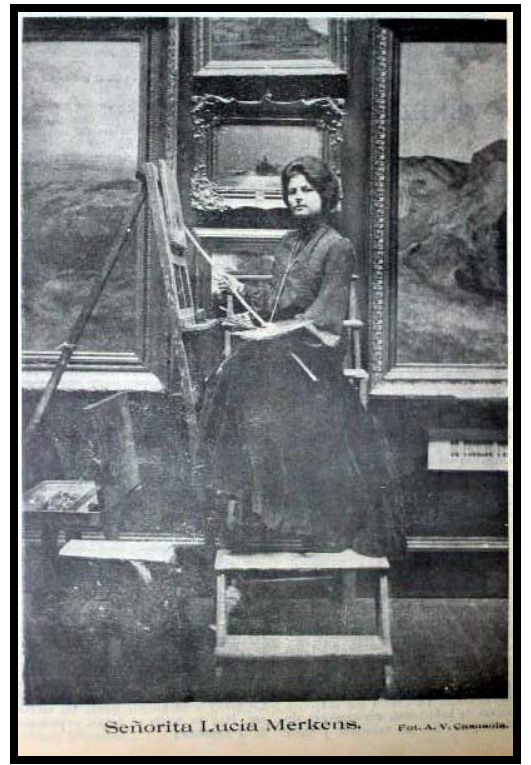

Imagen 10 - Srta. Lucía Merkens, en Semanario Literario Ilustrado, 24 de enero de 1904.

Aunque no se conocen muchos retratos de Agustín Casasola, él los realizaba muy probablemente tomando en cuenta la preceptiva del retrato de gabinete, aunque la intención fuera muy diferente a la de los retratistas de estudio. Otros retratos de Casasola acusan una composición que raya en lo ingenuo, como en el caso de los periodistas Reider y Galvani, que daban la vuelta al mundo en su bicicleta, ${ }^{22}$ o el que remite con mayor énfasis a las fotografías de estudio, como en el caso de la visita de los jefes Boers a la ciudad de México.

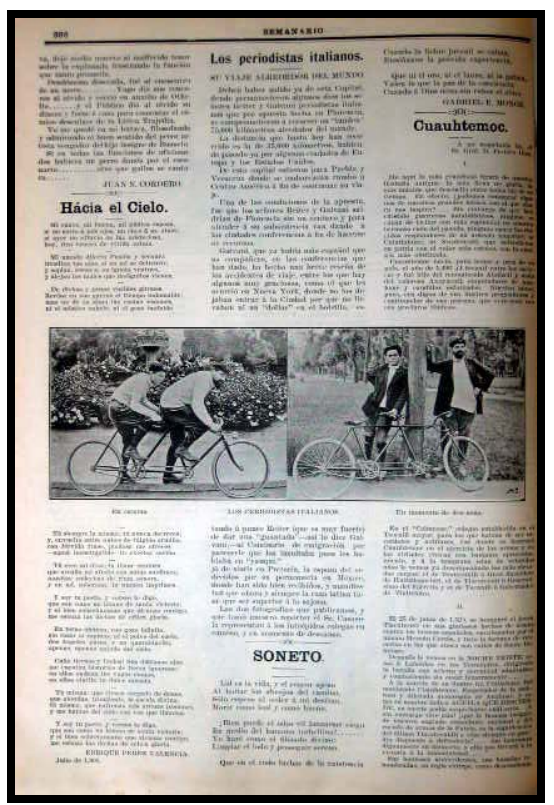

Imagen 11 - Periodistas Reider y Galvani en el Semanario Literario Ilustrado 19 de agosto de 1901. 1903.

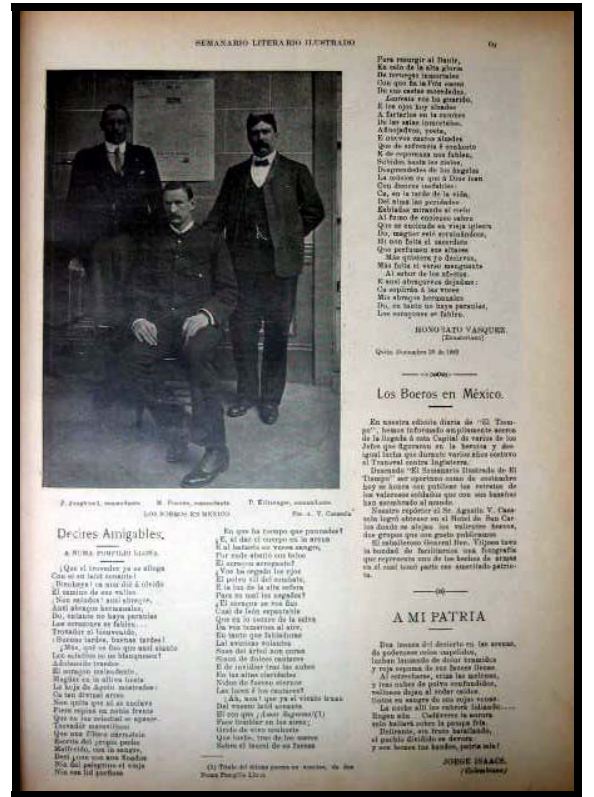

Imagen 12 - F. Jongbloed, comandante. M. Fouche, comandante. $P$. Kritzenger, comandante,

en Semanario Literario Ilustrado, 2 de febrero de 
En ambos casos los retratos tienen la impronta de la intencionalidad; es decir, la selección y arreglo de la escenografía, así como la pose de los retratados respondía ahora a una nueva intención del fotógrafo que es el destino de estas fotos hacia la prensa, y por lo tanto hacia la recepción casi inmediata y masiva de la imagen. El estudio del retrato en la prensa de los primeros años merecería un estudio aparte, lo cual rebasa los propósitos de este artículo.

Ante este panorama, es pertinente matizar la aseveración de que los primeros fotorreporteros en México eran simples empleados menores al servicio de algun redactor o editor del periódico. ${ }^{23}$ Todo indica que Agustín Víctor, por lo menos en sus años iniciales como fotógrafo, gozó de cierta libertad para "ilustrar" sus artículos. Me parece que esta situación se explica por su doble condición de redactor y de fotógrafo, y quizá por su cercanía amistosa con el director del periódico, Victoriano Agüeros.

Al parecer Agustín V. Casasola estuvo laborando en El Tiempo Ilustrado, hasta marzo de 1904, ya que en una carta que dirigió Victoriano Agüeros a Rafael Reyes Spíndola, director de El Imparcial, le comunica el deseo del reporter-fotógrafo para colaborar en El Imparcial. ${ }^{24}$ En efecto, entre marzo y julio de ese año aparece la última referencia de Casasola en El Tiempo, y a partir de ahí este semanario utiliza imágenes de distintos fotógrafos entre los que se encuentran: Emilio Lange, Schlattman, Ignacio Muñoz Flores, el American Photo Art Studio de Clarke, Foto Duhart y Guzmán; Duhart, Guzmán y Mario Duran, fots., Guillermo Valleto, Juan C. Hoyo, y C.B. Waite, entre otros.

Sin embargo, a partir de febrero de 1905, Agustín V. Casasola regresa a este semanario, con placas que remiten a las actividades cotidianas de la ciudad de México, muchas de las cuales las colocan como portadas de la publicación, entre ellas las relativas a la inauguración de la Escuela Militar de Aspirantes y del Hospital General, en la ciudad de México; a los funerales del embajador Manuel Aspiroz; y una vista de un carro alegórico en las fiestas del combate de las flores. ${ }^{25}$ No se conoce con certeza cual haya sido la relación laboral con el semanario, pero podría colegirse que se trataba de trabajos esporádicos, y no como fotógrafo de planta.

Visto lo anterior, me parece que el reconocimiento a los fotógrafos de la prensa no comenzó durante o después de la Revolución mexicana; más bien se trata de un fenómeno que se fue gestando desde la primera década del siglo $\mathrm{XX}$, por lo menos en publicaciones como El Tiempo Ilustrado. Cabe señalar que este reconocimiento no fue exclusivo para Agustín Víctor Casasola. Por ejemplo ya para el año de 1909, el semanario ilustrado de El Tiempo, comenzó a destacar el trabajo de su fotógrafo, 
Antonio Carrillo, como lo demuestra la alusión que los editores hicieron al premio que obtuvo, en ocasión del diploma de Honor obtenido "por sus trabajos fotográficoperiodísticos", en la exposición de Boston, Estados Unidos. ${ }^{26}$

Con ello se colige que los fotorreporteros anteriores a 1910 comenzaron a ser reconocidos, por lo menos, en el Semanario Ilustrado de El Tiempo, dado que sus múltiples imágenes se encuentran con el crédito respectivo, primero de Agustín V. Casasola, entre 1901 y 1905 y posteriormente de Antonio Carrillo entre 1905 y 1910. Si bien, no es un caso extraordinario ni único en el fotoperiodismo mexicano de aquellos años tempranos, si representa una aproximación a la condición del oficio de fotorreportero.

\section{Las fiestas del Centenario, continuidad de imágenes}

El año de 1910 es un año clave en la aprehensión de las imágenes, sobre todo por la celebración de las fiestas del centenario de la Independencia en México. Aquella fue una ocasión propicia para que el oficio de fotorreportero pudiera desarrollarse en encuadres y composiciones más libres de la ortodoxia que imponía la influencia de los fotógrafos de gabinete o de estudio. Para entonces, el gobernador del Distrito Federal, Guillermo de Landa y Escandón tuvo que expedir tarjetas de acreditación para los fotógrafos y periodistas que cubrirían los festejos del Centenario. ${ }^{27}$ Agustín Casasola fue registrado como fotógrafo de El Imparcial, junto con su hermano Miguel, con el propósito de que se les permitiera circular libremente por las calles de la ciudad de México durante septiembre de $1910 .^{28}$

Lo más rescatable del periodo, me parece, es el "boom" de imágenes y de fotógrafos, en una doble articulación: por un lado, cada fotógrafo realiza, en muchas ocasiones, series de fotografías de un acto, en una especie de "proto-reportaje gráfico" que para la década de 1930 tendrá su auge en México. Por otra parte, los actos oficiales fueron cubiertos por un numeroso contingente de reporteros en donde cada uno de ellos tuvo su versión gráfica de un mismo hecho. La mayoría de las veces los fotorreporteros estaban codo a codo y hombro a hombro, de tal forma que es muy difícil distinguir las imágenes de cada uno de ellos. Un sólo acto de las fiestas del centenario estaba cubierto por cinco, ocho o más fotógrafos. ${ }^{29}$

A pesar de que en 1910 ya se había extendido el uso de la película de nitrocelulosa, Agustín Casasola todavía utilizaba las placas de vidrio, incluso para actos en las orillas de la ciudad de México. Las cámaras fotográficas permitían introducir 
entre 20 y 30 placas de vidrio de 5 x 7 pulgadas, y de esta forma el fotógrafo tenía un número más grande de tomas. En todos los casos, los fotógrafos concebían una serie de fotografías, como una especie de seguimiento visual de algún acontecimiento específico.

En el caso de la ceremonia de inauguración de la Escuela Normal, en la ciudad de México, en septiembre de 1910, existen imágenes interesantes, que sin embargo no fueron publicadas en su momento. Es posible que El Imparcial haya enviado a este acto a Casasola, quien captó al menos diez placas del evento, no obstante sólo una fue publicada, como podemos observar en una de las páginas del periódico.

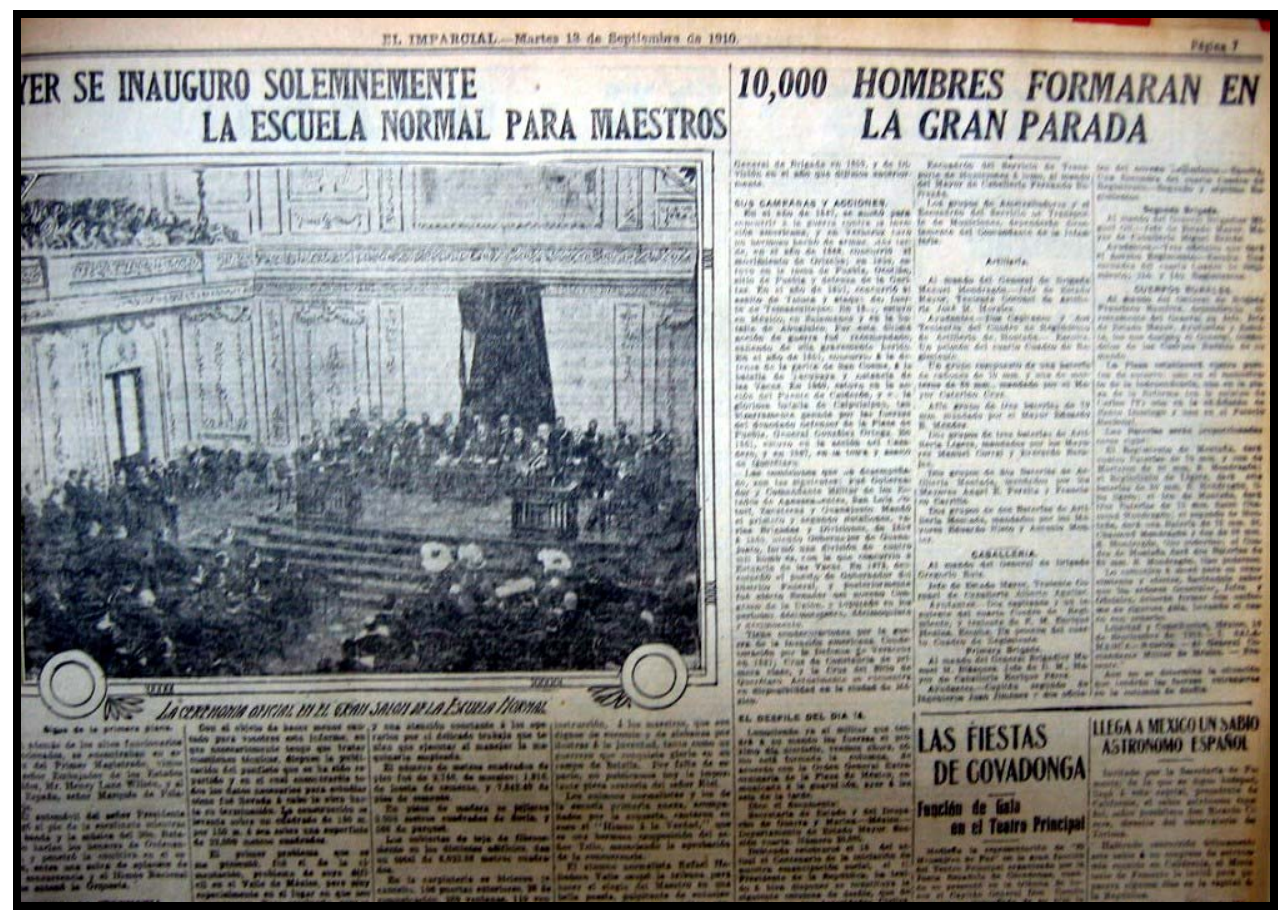

Imagen 13 - Ceremonia oficial de la inauguración de la Escuela Normal, en El Imparcial, 13 de septiembre de 1910.

Cabe destacar la imagen que eligió el periódico para que se publicase, en donde se observa un plano general de la ceremonia en un auditorio. No obstante, las otras placas que quedaron en el archivo de Casasola, constituyen un documento gráfico que da a conocer los interiores del edificio, o incorpora encuadres poco usuales, como la contrapicada en donde se retrata a Porfirio Díaz y su comitiva, en una composición muy moderna para la época.

Aunque los inicios del "proto-reportaje" se encuentran en el imaginario del fotógrafo, los periódicos aún no incorporan esta idea, quizá por la dificultad de procesar las fotografías en medio tono. Al respecto, en el Fondo Casasola encontramos imágenes 
captadas por Casasola que pudieran considerarse como series de un mismo evento, pero que en su momento el diario El Imparcial sólo publicaba una. Otro caso es el de la ceremonia de inauguración del edificio del Palacio Legislativo, el 23 de septiembre de 1910. Existen tres tomas realizadas por Agustín Casasola referente al momento de colocación de la primera piedra. En ellas se muestra la seriación que comenzaba en el trabajo de los fotorreporteros, pero que no aparecía en las publicaciones. De este grupo sólo la última, marcada con el número de inventario 35985, es la que apareció publicada en El Iparcial.

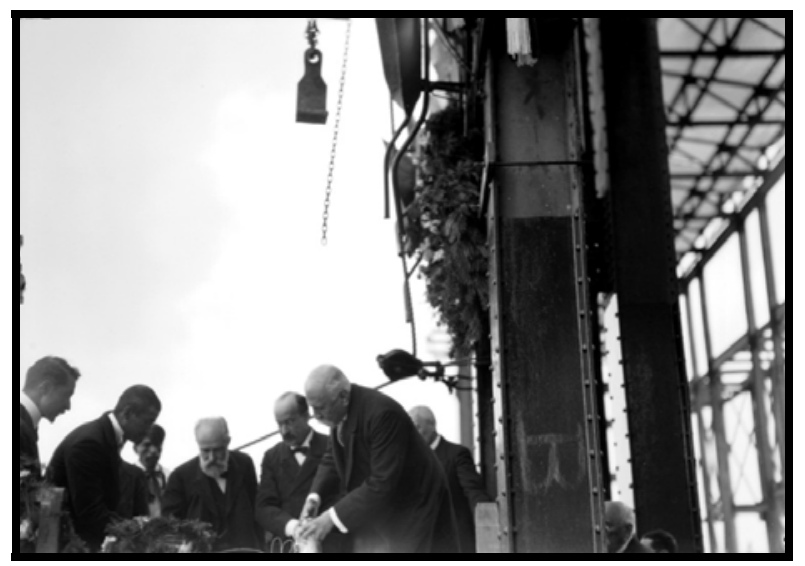

Imagen 14 - Ceremonia oficial de colocación de la primera piedra del Palacio Legislativo. No. Inv. 35981, Negativo de vidrio.

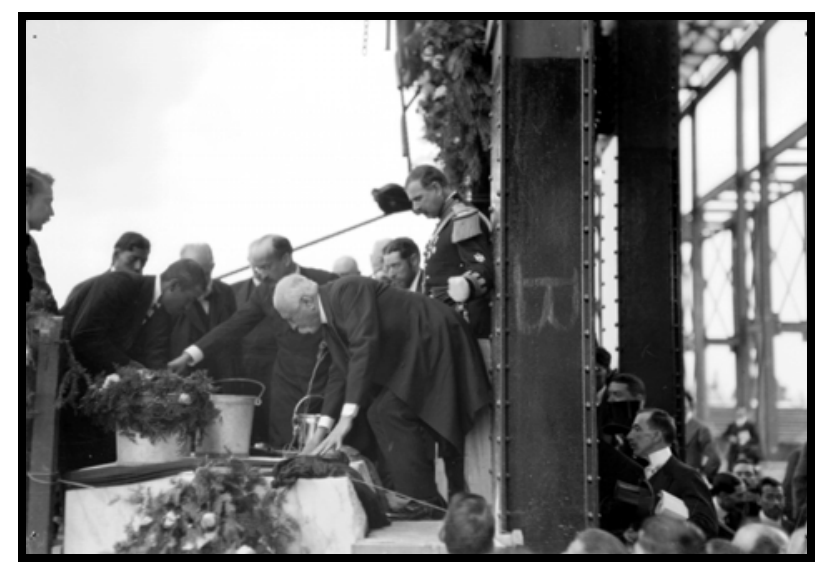

Imagen 15 - Ceremonia oficial de la colocación de la primera piedra del Palacio Legislativo. No. Inv. 35984, Negativo de vidrio. 


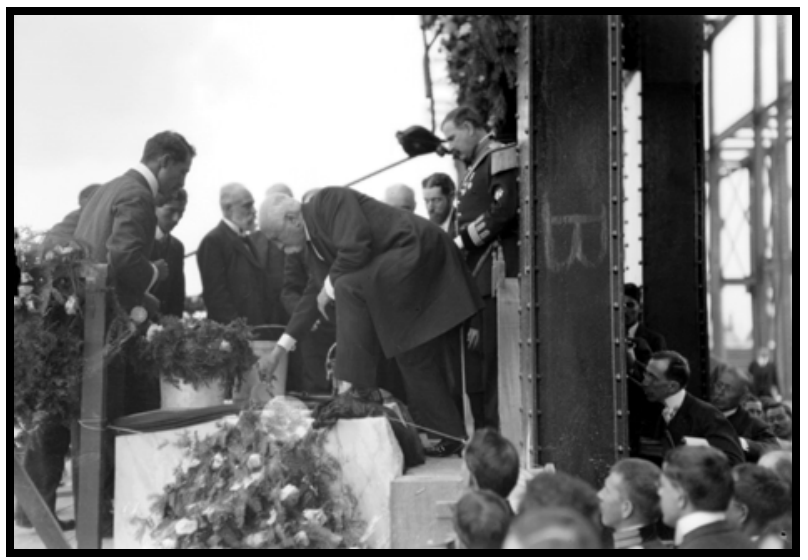

Imagen 16 - Ceremonia oficial de la colocación de la primera piedra del Palacio Legislativo. No. Inv. 35985, Negativo de vidrio.

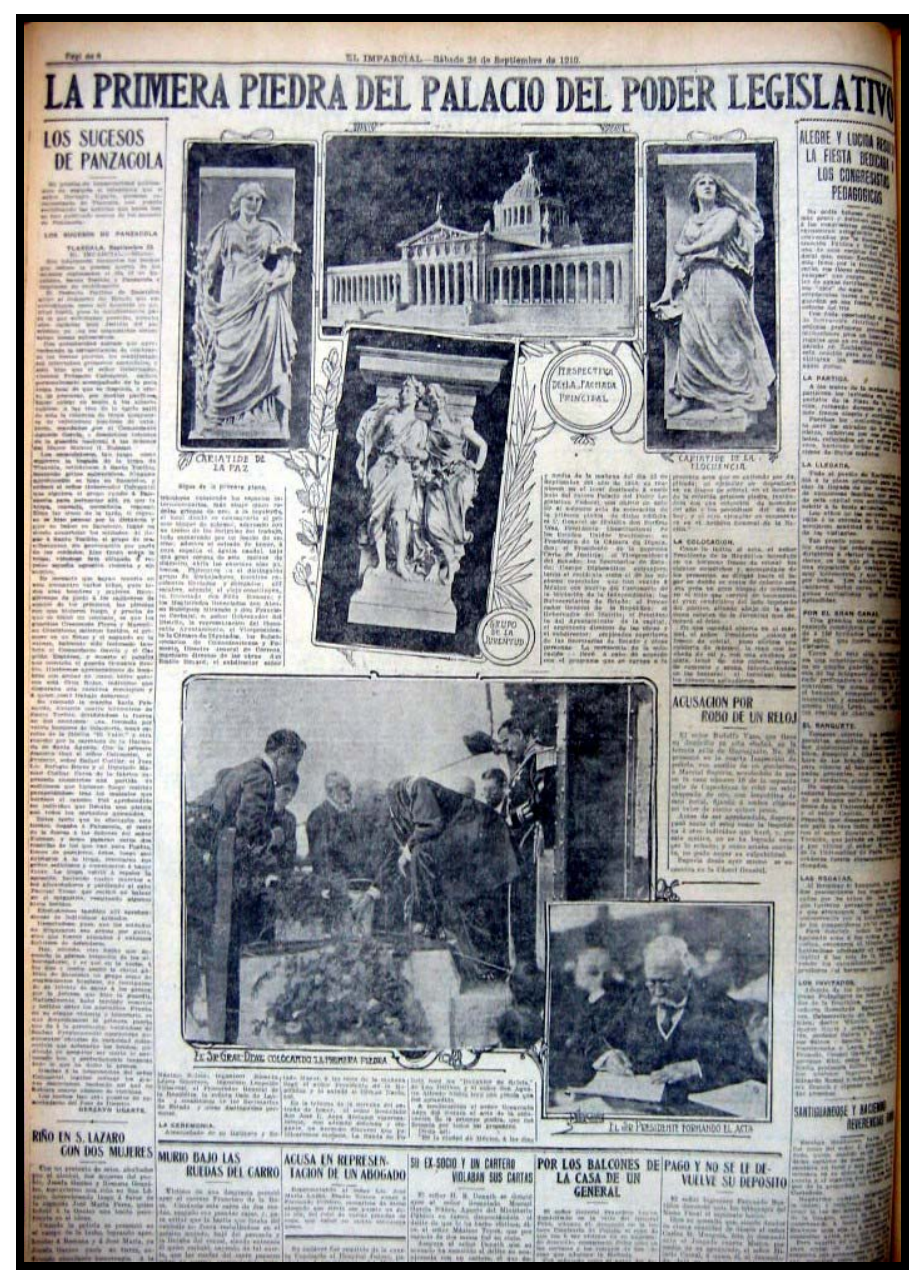

Imagen 17 - Ceremonia oficial de la colocación de la primera piedra del Palacio Legislativo, en El Imparcial, México D.F., 29 de septiembre de 1910. 
Vemos cómo para septiembre de 1910 ya se estaba consolidando un grupo de fotógrafos que acudían a los eventos fastuosos, como es el caso del desfile de inauguración de la Universidad de México, en el mismo septiembre de 1910. El fotógrafo que hace la toma desde un edificio quizá no es consciente de que está registrando el momento en que otros fotógrafos, a su vez, están retratando el mismo evento.

Al mismo tiempo, las fiestas del Centenario de la Independencia introducen nuevos actores sociales en la fotografía de prensa. Ahora ya no será únicamente el presidente Porfirio Díaz el personaje principal de las fiestas, sino que encontramos otras figuras, otros encuadres, y una intención de los fotógrafos de captar lo inmediato, lo que ocurría en las calles, lo cual constituía una práctica que aunque provenía de los años anteriores, se iba perfeccionando con la introducción de cámaras y negativos más funcionales para una actividad como la del fotoperiodismo.

Así, tenemos a Agustín Casasola, ya como fotógrafo de prensa, y quien un año después de las fiestas del Centenario, en 1911, fundaría la Asociación de Fotógrafos de Prensa, para que posteriormente, en una fecha incierta del año de 1912, crearía también la primera agencia de fotografías destinadas a suministrar imágenes a los periódicos y revista de la época. Me parece que estos años que hemos revisado someramente ilustran la nueva forma de mirar a través de las cámaras fotográficas. Los fotógrafos, en especial Agustín Casasola, comenzaron a crear un nuevo lenguaje gráfico, en razón de que sabían que su producto se visualizaría al día siguiente, o a la semana siguiente, por cientos, o miles de personas.

\section{A manera de conclusión}

La mayoría de los fotógrafos de periódicos, llamados en sus comienzos "reporter-fotógrafo", que trabajaron en México, desde finales del siglo XIX y principios del XX, comenzaron por desterrar la figura del fotógrafo de estudio, para dedicarse a crear una estética propia, más acorde con la noticia inmediata, con la noción de instantaneidad, y con la verosimilitud de la noticia. A estas fotografías, al momento preciso de la toma fotográfica le hemos denominado la "captura del momento". 
Precisamente, Agustín Casasola fue uno de los fotógrafos que inició en el oficio de reportero, y transitó al de fotógrafo de prensa, de tal manera que ya para 1910 se había consolidado como uno de los más influyentes fotorreporteros de la ciudad de México.

Durante estos años, entre 1901 y 1910, la vida cotidiana en la ciudad de México parecía repetirse en ciclos, y los fotógrafos acusaba esa dinámica de fotografias los mismos eventos de cada año en un tiempo circular. Es revelador lo que señala el periódico El Imparcial, respecto a las fiestas del 5 de mayo: "Nada de notable hubo en ellas, pues el programa fue como todos los años: todo se redujo a discursos y al consabido desfile de tropas". ${ }^{30}$ De esta forma, los fotógrafos como Casasola tuvieron varios escenarios al aire libre para poducir sus instantáneas, por ejemplo en la conmemoración de fiestas y ceremonias cívicas, como la ya mencionada del 5 de mayo, la del 2 de abril, el aniversario luctuoso de Juárez, o las fiestas de la independencia en el mes de septiembre.

En tal sentido, la práctica fotoperiodística en México se fue constituyendo en un proceso gradual que proviene de los últimos años del siglo XIX y que ya para la década de 1910 tenía un largo camino recorrido. Esta aseveración no comparte la idea de que la Revolución cambió la "forma de ver", o que a raíz del movimiento armado iniciado en 1910 aparecen nuevos actores sociales. Más bien, me parece que durante la primera década del siglo XX los fotorreporteros de las publicaciones periódicas fueron depurando y desarrollando una visualidad que partía de la noticia coditiana y de la fotografía como certificado de veracidad.

\section{Selección de imágenes}

1.- Hoja del Semanario Literario Ilustrado, México, D.F., lunes, 13 de mayo de 1901. Fotos de Agustín V. Casasola.

2.- Porfirio Díaz en el muelle de Veracruz. Negativo gelatina sobre vidrio, no. de inventario 34478. Fondo Casasola, Fototeca Nacional, INAH.

3.- Porfirio Díaz abordando el bote Nereidas. Negativo gelatina sobre vidrio, no. de inventario 34484, Fondo Casasola, Fototeca Nacional, INAH 
4.- Hoja del Semanario Literario Ilustrado, 21 de octubre de 1901, "Los ferrocarriles eléctricos, una visita a la planta de la Indianilla". Fotos de A. V. Casasola.

5.- Portada del Semanario Literario Ilustrado, lunes, 27 de abril de 1903. Fotografía de A.V. Casasola.

6.- Portada del Semanario Literario Ilustrado, lunes, 9 de noviembre de 1903. Fotografía de A. V. Casasola.

7.- Porfirio Díaz en la mina de la Valenciana. Negativo gelatina sobre vidrio, No. Inv. 5305, Fondo Casasola, Fototeca Nacional, INAH.

8.- Hoja, Semanario Literario Ilustrado, lunes, 24 de septiembre de 1905. Fotos de A.V. Casasola.

9.- Porfirio Díaz, en la ciudad de México. Negativo gelatina sobre vidrio, no. de inventario 5749, Fondo Casasola, Fototeca Nacional, INAH.

10.- Semanario Literario Ilustrado, lunes, 24 de enero de 1904. Retrato de la Srita. Lucía Merkens.

11.- Hoja, Semanario Literario Ilustrado, lunes, 19 de agosto de 1901. Periodistas Reider y Galvani. Foto de A.V. Casasola.

12.- Hoja, Semanario Literario Ilustrado, lunes, 2 de febrero de 1903. Los jefes boers F. Jongbloed, M. Fouche, y P. Kritzenger. Fotografía de A. V. Casasola.

13.- Hoja, El Imparcial, 13 de septiembre de 1910. Ceremonia de inauguración de la Escuela Normal.

14.- Ceremonia oficial de la colocación de la primera piedra del Palacio Legislativo. Negativo, gelatina sobre vidrio, No. Inv. 35981. Fondo Casasola, Fototeca Nacional, INAH. 
15.- Ceremonia oficial de la colocación de la primera piedra del Palacio Legislativo. Negativo, gelatina sobre vidrio, No. Inv. 35984. Fondo Casasola, Fototeca Nacioal, INAH.

16.- Ceremonia oficial de la colocación de la primera piedra del Palacio Legislativo. Negativo, gelatina sobre vidrio, No. Inv. 35985. Fondo Casasola, Fototeca Nacional, INAH.

17.- Hoja de El Imparcial, México D.F., 29 de septiembre de 1910. Ceremonia oficial de la colocación de la primera piedra del Palacio Legislativo, en El Imparcial.

\section{REFERÊNCIAS BIBLIOGRÁFICAS:}

ALTÚZAR, Mario Luis. “Agustín Víctor Casasola, cazador de instantes históricos”. En Agustín Victor Casasola, el hombre que retrató una época, 1900-1938, México, Gustavo Casasola, 1988.

ANCIRA, Eduardo. "Fotógrafos de la luz aprisionada. Asociación de Fotógrafos de la prensa metropolitana de la ciudad de México, octubre-diciembre de 1911”. En Fernando Aguayo y Lourdes Roca, Imágenes e Investigación social, México, Instituto Mora, 2005, pp. 334-353.

ARNAL, Ariel. La fotografía del zapatismo en la prensa de la ciudad de México, 19101915. 2001. Tesis de maestría en historia, México, Universidad Iberoamericana.

CASTILLO, Alberto del. "La historia de la fotografía en México, 1890 y 1920”. En Imaginarios y fotografía en México, 1839-1970, coord. Emma Cecilia García Krinsky, México, Lunwerg, 2005.

FREUND, Gisele. La fotografia como documento social, Barcelona, Gustavo Gilli, 1993.

MONROY NASR, Rebeca. Historias para ver. Enrique Díaz, fotorreportero. México, Instituto de Investigaciones Estéticas. UNAM, 2003.

MONTELlANO, Francisco. Charles B. Waite, la época de oro de las postales en México. México, Conaculta, Círculo de Arte, 1998.

MUSACCHIO, Humberto. "La fotografía de prensa. Apuntes para un árbol genealógico". En revista Kiosko, año III, num. 3, 1992, 
NIETO SOTELO, Jesus, et al. La Linterna Mágica en México. México, UAEM. Ediciones Sin Nombre, 2003.

REYES, Aurelio de los. Cine y sociedad en México, 1896-1930. Volumen I, Vivir de sueños, 1896-1920. México, Instituto de Investigaciones Estéticas. UNAM, 1996.

Hemerografía:

El Imparcial, México D.F., 1905-1910

Semanario Literario Ilustrado, México, D.F., 1901-1910

ESCORZA RODRÍGUEZ, Daniel. The photo-journalistic itinerary of Agustín Victor Casasola, 1901-1910. História, São Paulo, v. 26, n. 2, p. 19-42, 2007.

Abstract: My intention in this article is to review, through a monographic case, the assertion of which with the initiated revolutionary movement in 1910 new facts and new forms of photography were registered. Through a work like the one of Casasola which we will cross in little more than 10 years, from 1901 to 1913, we will review the main changes, the continuities and the visibility that went developing in these decisive years for the history of the photography in Mexico.

Keywords: Photography, Photographer, Mexican Revolution, Agustin V. Casasola

Artigo recebido em 08/2007. Aprovado em 11/2007.

\section{NOTAS:}

\footnotetext{
* Fototeca Nacional INAH

1 Véase Alberto del Castillo, "La historia de la fotografía en México, 1890 y 1920". En Imaginarios y fotografia en México, 1839-1970, coord. Emma Cecilia García Krinsky, México, Lunwerg, 2005, p. 67. Para el acercamiento a la tarjeta postal, a las estereoscópicas y al cine, véanse respectivamente: Francisco Montellano, Charles B. Waite, la época de oro de las postales en México, México, Conaculta, Círculo de Arte, 1998; Jesus Nieto Sotelo et al., La Linterna Mágica en México, México, UAEM, Ediciones Sin Nombre, 2003; y Aurelio de los Reyes, Cine y sociedad en México, 1896-1930. Volumen I, Vivir de sueños, 1896-1920, México, Instituto de Investigaciones Estéticas, UNAM, 1996.

2 Alberto del Castillo, op. cit., p. 67

$3 \mathrm{Al}$ respecto, por ejemplo, el mismo Castillo dice que "el surgimiento de la violencia revolucionaria en 1910 terminó con el sueño de perpetuidad del gobierno porfiriano. Los fotógrafos salieron a las calles a registrar los nuevos hechos y acontecimientos, enfrentando retos técnicos y tareas cada vez más complejas", op. cit., p. 72. Además un buen número de bibliografía especializada coincide con este aserto. Véase Rebeca Monroy, Historias para ver. Enrique Díaz fotorreportero, México, Instituto de
} 
Investigaciones Estéticas, UNAM, 2003, p. 30.

4 Mario Luis Altúzar, "Agustín Víctor Casasola. Cazador de instantes históricos", en Agustín Víctor

Casasola, el hombre que retrató una época, 1900-1938, México, Gustavo Casasola, 1988, p. 12.

5 Véase Eduardo Ancira, "Fotógrafos de la luz aprisionada. Asociación de Fotógrafos de la prensa metropolitana de la ciudad de México, octubre-diciembre de 1911". En Fernando Aguayo y Lourdes Roca, Imágenes e Investigación social, México, Instituto Mora, 2005, pp. 334-353.

6 A partir del 25 de febrero de 1901, el nombre del semanario cambia a Semanario Literario Ilustrado, "dedicado a las familias católicas". De manera general se le conocerá como El Tiempo Ilustrado.

7 En el caso de nuestro semanario, desde el primer número algunas fotos tienen las siglas de MI, Miguel Ibarra, quien elaboraba las placas fotográficas en el clissé, y quien sería sustituído posteriormente por otro fotograbador: Armando Salcedo. Es importante diferenciar entre ambas actividades: la del fotograbador y la del fotógrafo, las cuales inicialmente compartían la misma jerarquía y destreza.

8 Semanario Literario Ilustrado, lunes, 13 de mayo de 1901, p. 227. Las cursivas son mías.

9 Semanario Literario Ilustrado, lunes 23 de septiembre de 1901, p. 438. El artículo no está firmado, pero se colige que el autor es Agustín V. Casasola, porque a las fotografías se les da el crédito correspondiente. Las cursivas son mías.

10Todos los textos al respecto repiten el lugar común de que Agustín Víctor "cambió la pluma por la cámara fotográfica", en 1900. Véase, Mario Luis Altúzar, "Agustín Víctor Casasola, cazador de instantes históricos", op. cit., p. 12. también Humberto Musacchio, "La fotografía de prensa. Apuntes para un árbol genealógico". En revista Kiosko, año III, num. 3, 1992, p. 34. Sin embargo, como podemos observar, en El Tiempo Ilustrado, entre 1901 y 1904 todavía combinaba ambas actividades: la de reportero y la de fotógrafo.

11 Semanario Literario Ilustrado, lunes, 17 de marzo de 1902, p. 155-158.

12 Esta asociación se formó el 4 de octubre de 1903, y funcionaba como una especie de sociedad mutualista, o de ayuda gremial. Véase Altúzar, op. cit., p. 9, y Seis siglos de historia de México, México, Gustavo Casasola, p. 1892.

13 Véase Semanario Literario Ilustrado, lunes, 9 de febrero de 1903, p. 165.

14 Las cursivas son mías. Artículo firmado por Agustín V. Casasola, "Los ferrocarriles eléctricos, una visita a la planta eléctrica de La Indianilla". En Semanario Literario Ilustrado, lunes, 21 de octubre de 1901, p. 508.

15 Ariel Arnal, La fotografía del zapatismo en la prensa de la ciudad de México, 1910-1915. Tesis de maestría en historia, México, Universidad Iberoamericana, 2001, p. 157.

16 Aparece en el Semanario Literario Ilustrado, en su edición del lunes 27 de abril de 1903.

17 Semanario Literario Ilustrado, lunes, 9 de noviembre de 1903. Portada.

18 La placa se encuentra en el Fondo Casasola de la Fototeca Nacional, Inv. 5305, que es un negativo de gelatina sobre vidrio de $5 \times 7$ pulgadas.

19 Aurelio de los Reyes, Cine y sociedad en México,1896-1930. Volumen I, Vivir de sueños, 1896-1920. México, Instituto de Investigaciones Estéticas, UNAM, 1996, p. 54.

20 El Tiempo Ilustrado, lunes 1 de enero de 1906.

21 El Tiempo Ilustrado, Domingo, 24 de enero de 1904, p. 73. El semanario argumentó la inclusión de esta foto en el sentido de que: "Como el conjunto de dicha fotografía es interesante, no vacilamos en publicarla como nota de arte."

22 Una de las fotografías publicadas en el Semanario Ilustrado, al respecto del viaje de los periodistas italianos, se ha localizado en el Fondo Casasola, y se trata de un negativo gelatina sobre vidrio, no. de inventario 196274.

23 De acuerdo a Gisele Freund, muchos de los primeros fotógrafos de prensa eran aficionados que usaban la foto para dar mayor credibilidad a sus artículos, y se formaban sobre la marcha. Sobre las fotos señalaba que: “... Ninguna de estas fotos iba firmada por sus autores y el estatuto del fotógrafo de prensa recibió durante casi medio siglo una consideración inferior, comparable al de un simple criado a quien le dan órdenes sin poder de iniciativa" (Gisele Freund, La fotografia como documento social, Barcelona, Gustavo Gilli, p. 98). Como se puede observar, Casasola estuvo lejos de ser un "simple criado" al servicio de un periódico.

24 Altúzar, op. cit., p. 9.

25 Véanse las portadas de El Tiempo Ilustrado, todas del año de 1905: domingo, 5 de febrero, domingo, 12 de febrero, domingo, 30 de abril y 14 de mayo, respectivamente.

26 El Tiempo Ilustrado, 17 de enero de 1909, p. 46. Antonio Carrillo laboraba como fotógrafo en este semanario, y para el año de 1908 ya se le otorgaba el crédito en el directorio del periódico como "Fotógrafo".

27 Ancira, Eduardo, op. cit., p. 349

28 Ibid., p. 347.

29 De los periódicos y revistas de la ciudad de México que registraron o acreditaron fotógrafos para las Fiestas del Centenario tenemos a: El Imparcial, El Tiempo, El Tiempo Ilustrado, El País, El Diario, La 
Patria, Gil Blas, El Mundo Ilustrado, La Semana Ilustrada, Revista Ilustrada del Centenario, El Paladín, La Nobleza, entre otros

30 El Tiempo Ilustrado, México, D.F., 12 de mayo de 1907. p. 3. 